\title{
Design and Research on Writing and Testing Training System Geared to Practical Writing \\ YU Changchun ${ }^{1, a}$ \\ ${ }^{1}$ Foreign Language School, Wuhan Polytechnic, Wuhan 430074, P.R China \\ aliliang109@126.com
}

Keywords: practical writing, writing and testing training system, internet

\begin{abstract}
Practical writing is one of the most important targets to test students' ability to learn and apply presentation skill; an important reference index to detect practical language ability of students. In order to enhance the level of students' practical writing ability, tend to the demands for students' application of flexible technology and the development of their own learning, writing test platform based on intelligent Web comes into market. With the aid of modern Internet technology, people develop the platform for the new writing, which makes the way of writing cultivated in the case of electronic paperless teaching and examination of the mission plan. The platform quickens simplification of training process of the writing training and management, and provides great convenience for the assessment and provides of students. The writing and testing system based on intelligent Web implements the writing and testing ability can combine according to the difficulty and ability, and objectively summarize the learning situation of students in the test results, and finally find a comprehensive solution.
\end{abstract}

\section{General introduction of practical writing}

\section{The relevant theories of practical writing}

From our present definition, practical writing refers to practical value and the standard format of the document used by state organs, party and government departments, institutions, social organizations and the masses of the people in the work, study and life in order to deal with a variety of public and private affairs. In ancient China, articles are originated from utility. The first articles were written for certain functions. Like Plekhanov said that people originally look at things from the point of utilitarian and phenomena, only later to the point of aesthetic. And this kind of functional articles are indispensable in all ages.

But with the changes of The Times, the practical writing style has greatly changed. Broadly, the ancient practical writing is to solve practical problems, targeted state some cases, and it has specific readers and fixed styles, such as dredging, imperial edicts, answers, book calves, applied forms, chapter article inscription, infighting, table and lies, house and so on. In short, it is the product of practice, just as its name implies that "function" is its content and "writing" is its fixed form. No matter how changes of the ancient and modern styles, the common features of the function of practical writing styles is practical application.

\section{The meaning of practical application writing}

Practical writing puts emphasis on the word "practical application", which is the main characteristic that differs from other genres. "Practical" means the promise and "application" is function, usage and adhibition. "Practical' and "application" determine the basic properties of the practical application writing, but it also has the general connotation of writing. It is for the purpose of solving the problems arising from the production, study, work and life, which has direct application value. The meaning of the practical application writing should be: a unit of articles with a certain format formed and used by individual or company in handling affairs, communication relations. 


\section{The writing and testing system}

\section{Demand analysis of forming the writing and testing system}

With the continuous development of computer network and the network technology, the original writing and testing training model cannot meet the needs of large-scale online learning and testing. And we also won't test and correct the students' test operation using a traditional way to print like before, but use network with very fast communication speed to achieve online learning and test, this kind of writing and testing requires students more writing and testing resources.

The kind of online learning and testing system needs not only the general functions in learning platform, but also intelligent features of test system, which mainly includes:

(1) In the system, students can take the test after finished learning, and then they submit the test training assignments. The system will give the test results immediately of the questions belonging to the objective part and point out the error points and the covering knowledge. And the subjective writing test will be corrected by the teacher in the specified time and the results will be given to the students by email online.

(2) In the test stage of training, the exercises in the question data will be classified according to the grades of difficulty of application ability. When students pick test questions online, it can randomly generate the test, so students can learn according to their own situation to easy writing level of the application system choice and the ability to distinguish the degree examination.

\section{Analysis of functional model of the system}

According to the two functions of this system, one is writing online function, the other one is testing function, the system then is divided into two parts: the general testing module, which is mainly composed of landing module, testing module, checking module, the administrator management module, test administrators to manage students module, management module and writing auxiliary function modules for teachers and students, and the writing online platform includes seven basic modules which are the platform landing and backstage management, the thesis topic distribution and submission, review, exemplary display, writing theory, BBS, and resources links. All these basic modules cover the basic requirements of writing online training system, which is shown as the following chart 1:

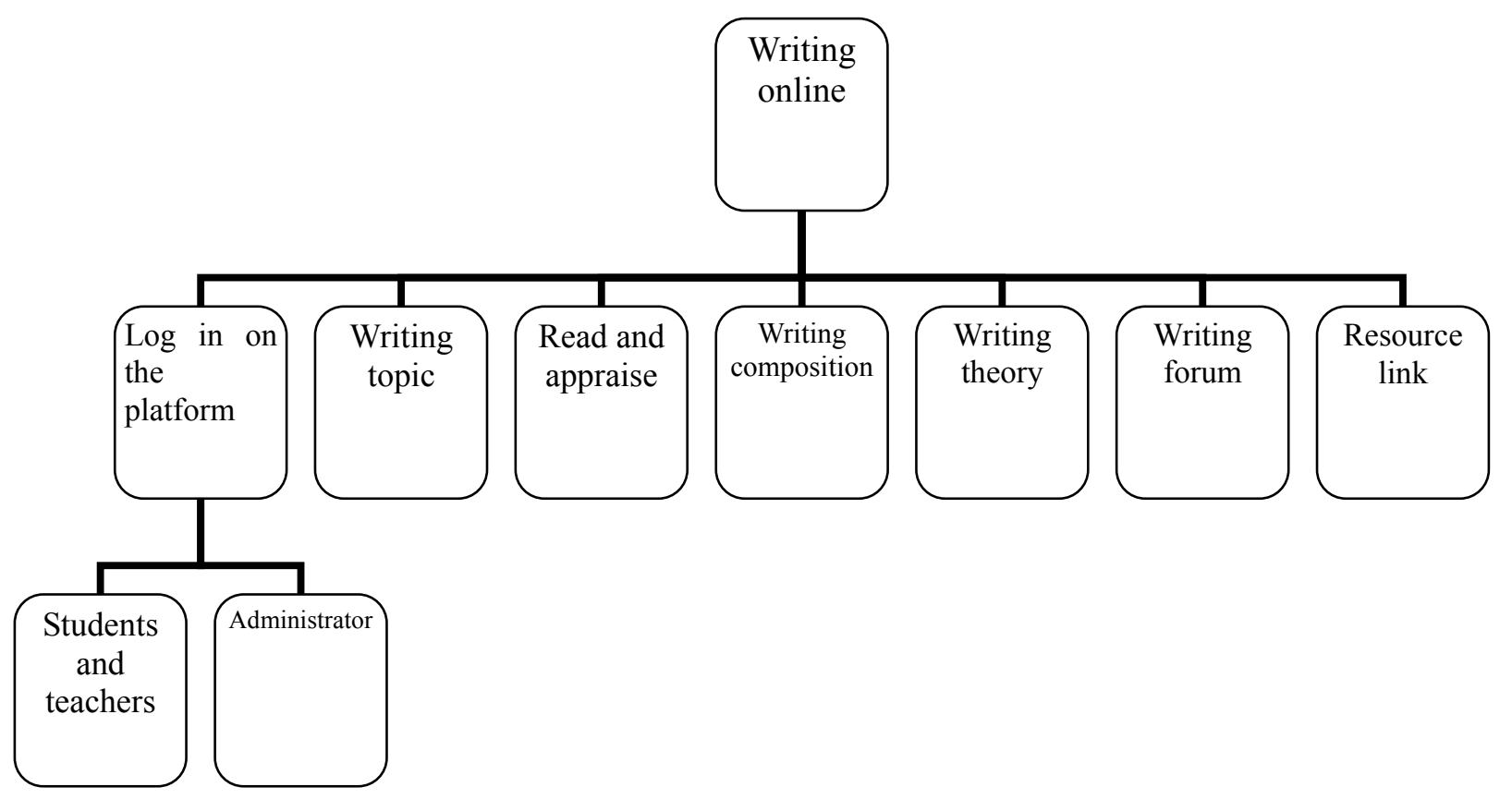

Chart 1: the structure of system in the writing online functional model

For online writing module, login interface is the entrance into the platform between teachers and students. Teachers may register or not; also user name, password, and class can be assigned by the administrator; students need to register. When filling out the registration information, students must pay attention to the optional class and the teacher. The moment the system shows the registration dialog, the student's file is associated with the corresponded teacher permissions. Background 
management is the specialized channel for platform administrator, where user management, modifying, and deleting various kinds of information happens in the system as the senior administrator. Main function of the performance management module is the administrator can view the students' test; respectively statistics fail and pass the number of people, shown in Chart 1.

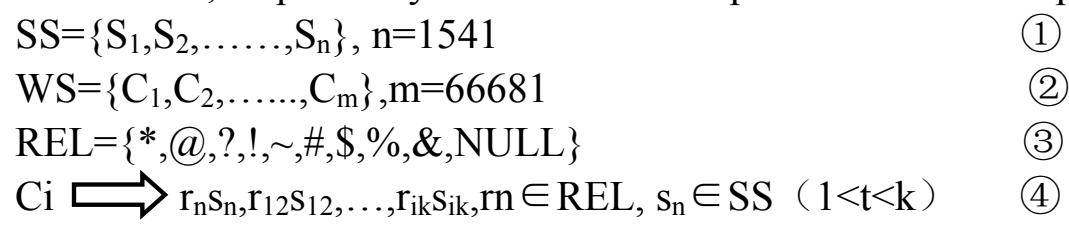

SS means the original collection, and the collection REL is possible relationship between concepts between the original set. Some information for $\mathrm{C}_{\mathrm{i}}$, its result is composed of $\mathrm{k}$ items; each item is a symbolic relationship of the original plus righteousness.

\section{Comprehensive design and plan of the writing and testing system}

This system is divided into writing online function module and testing online function modules to design the whole system, the following is our specific introduction of the design and plan of the system.

\section{Writing online function module}

Writing teaching mode of network technology based on ASP.NET includes teachers and students, PC terminal, operating system, and the Internet etc. Through this kind of writing and testing mode, the teachers and students need to master basic network and skilled computer operation knowledge. Therefore, the framework of online writing center is shown in chart 2:

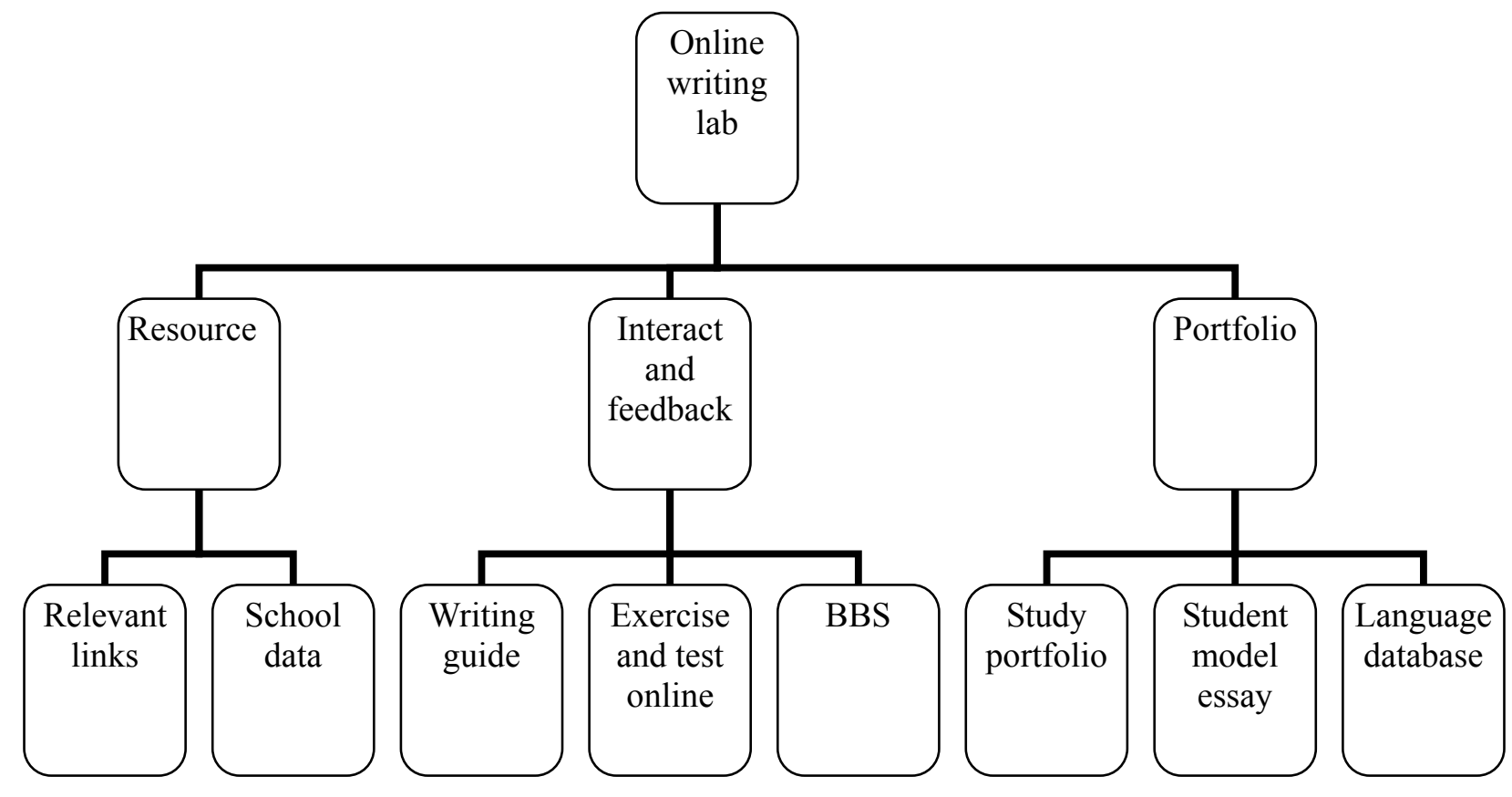

Testign online function module

Chart 2: structure of writing online platform

The testing function module mainly includes six sub modules: the landing module, test module, check module, the administrator test management module, the administrator student management module, score management module.

System maintenance module often requires for the student data table when the user login and manage the password and access according to the data in the student table. After login, all operations are done by the user of login as the operator. The questions table is used to store some judgment topics, when students are required to attend the test; he may answer the questions randomly selected from the table by the information such as table 1: 
Table 1: data sheet of the writing application

\begin{tabular}{|l|l|l|l|l|}
\hline NO & Filed name & Type of data & Length & Description \\
\hline 1 & Wid & Varchar & 10 & No of questions \\
\hline 2 & Wquestion & Varchar & 10 & Question \\
\hline 3 & Wanswer & Varchar & 20 & Answer \\
\hline 4 & Wpoint & Varchar & 2 & Score \\
\hline 5 & WNumber & Single & 5 & Difficulty \\
\hline
\end{tabular}

\section{Design of the structure application process of the system}

For higher intelligent writing and testing system, there are two main functions: one is the online writing training; the second is practical ability test of the entire process refers to the user use the system to carry out the activities of the program. After the operation of the system, the first to see is the landing window to confirm the information of users.

Authentication process is as follows:

(1) To understand whether the user's identity is effective;

(2) To confirm which kind of user belongs to.

The first stage is to determine whether the user is allowed to use system and the second phase is in accordance with the categories identified which operations that a user has the rights to do of specific process as shown in chart 3:

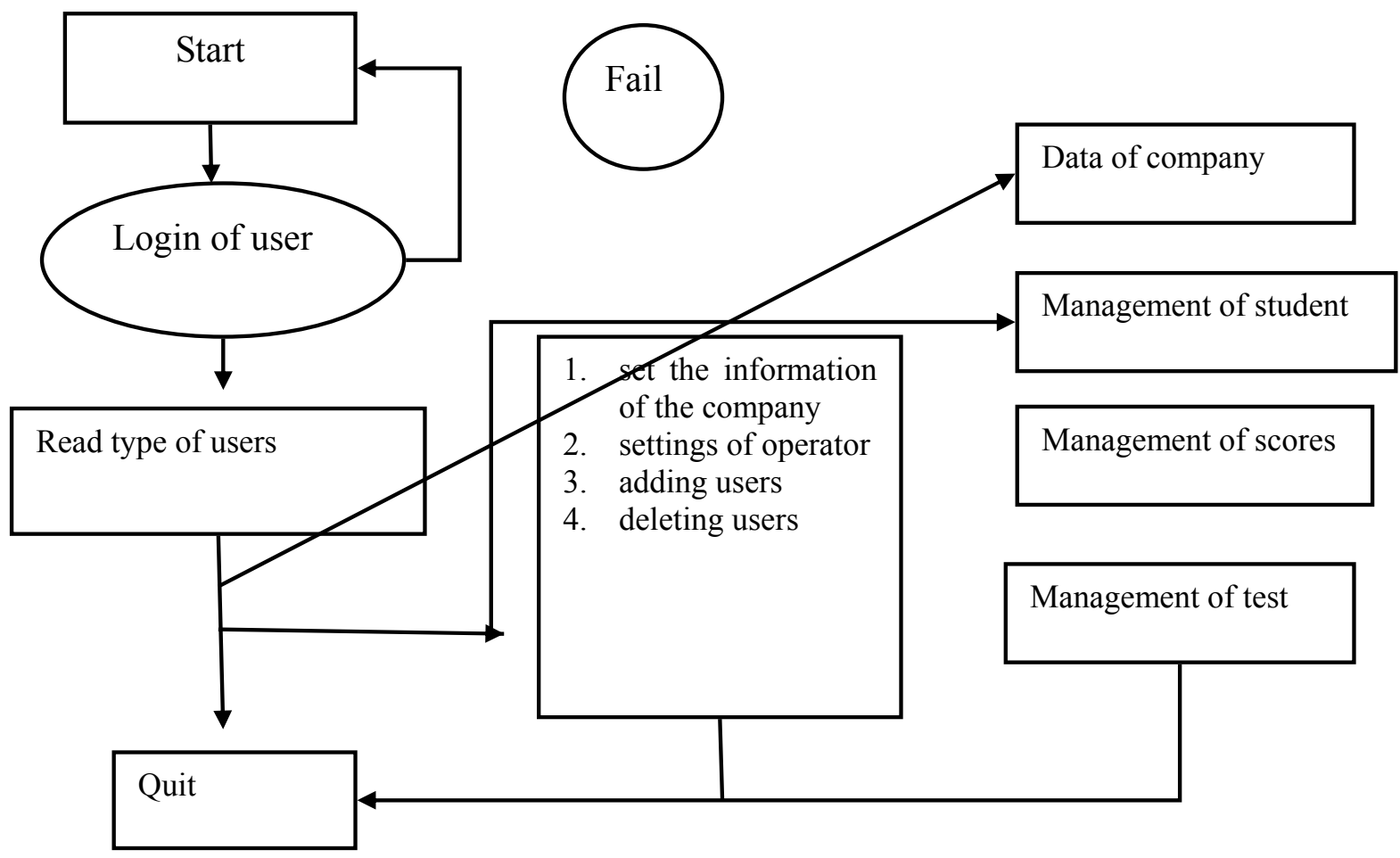

Chart 3: the structure application process of the system

\section{Summary}

From the traditional writing and teaching as well as the double model with the combination of network teaching and testing, we find that writing and intelligent test system based on WEB not only promotes the interactive communication of information under the network technology, and diversification of the self-evaluation test way. The various writing resources and assessment systems in the system improve the quality of the writing test efficiency.

Writing teaching and test training system based on intelligent network is achieved through the usage of network resources and technology of modern education, education mode. It adopts the 
network remote online learning focusing on characteristics of the original writing assessment, which optimizes the writing teaching and test resources, makes students to transfer the subjective initiative in learning and self-evaluation to an extreme.

\section{References}

[1] Jeffrey A. Hoffer, University of Dayton, Joey F. George. Modern Systems Analysis and Design [M], Third Edition. Pearson Education, 2003.4: 45-50.

[2] Wang Xiaoyi, Examples of the Development of JSP Database[M]. Beijing: Electronic Industry Press, 2005,2:43-48.

[3] Hector Garcial -Molina, Jeffrey D. Ullman, Jennifer Widom, An introduction to Database Systems (Seventh Edition)[M]. Beijing: China Machine Press,2001:90-101. 